\title{
CORRIGENDUM
}

\section{Estimation of abdominal fat compartments by bioelectrical impedance: the validity of the ViScan measurement system in comparison with MRI}

\author{
EL Thomas, AL Collins, J McCarthy, J Fitzpatrick, G Durighel, AP Goldstone and JD Bell \\ European Journal of Clinical Nutrition (2011) 65, 284; doi:10.1038/ejcn.2010.237
}

Correction to: European Journal of Clinical Nutrition (2010) 64, 525-533; doi:10.1038/ejcn.2010.18

Since the publication of this paper, the authors have noticed an error in the labelling of Figure 4 . The correct figure legend is shown below.
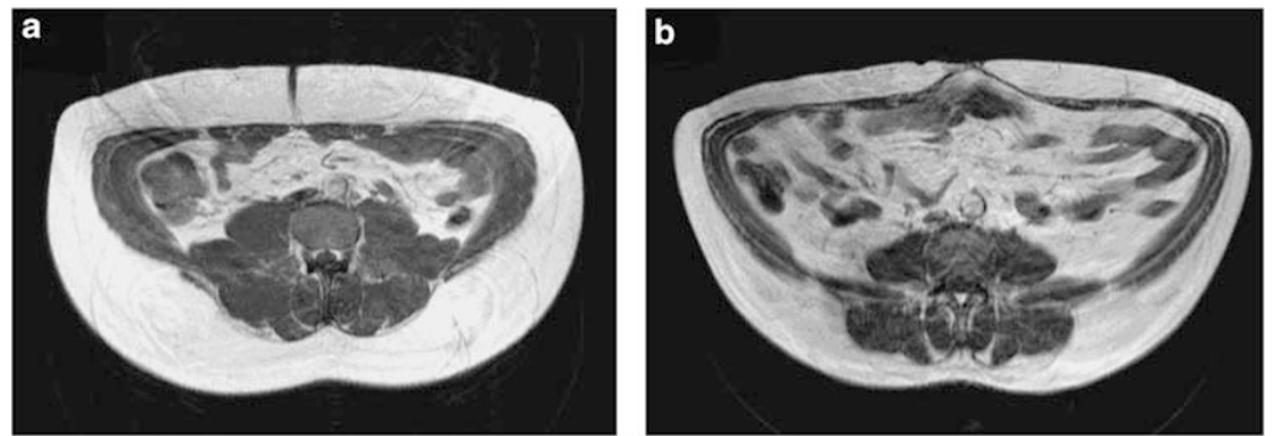

Figure 4 A single-slice MRI image for two subjects of the same gender with near-identical ViScan visceral fat scores $(\mathbf{a}=19.5 ; \mathbf{b}=20$ arbitrary units) but differing IAAT as assessed by MRI $(\mathbf{a}=3.2 ; \mathbf{b}=6.3 \mathrm{I})$. Interestingly, when abdominal subcutaneous fat was considered ( $\mathbf{a}=13.6$; $\mathbf{b}=9.2 \mathrm{I})$, these two subjects showed similar overall levels of total abdominal adiposity $(\mathbf{a}=16.8 ; \mathbf{b}=15.5 \mathrm{I})$. 